\title{
Lenz microphthalmia syndrome?
}
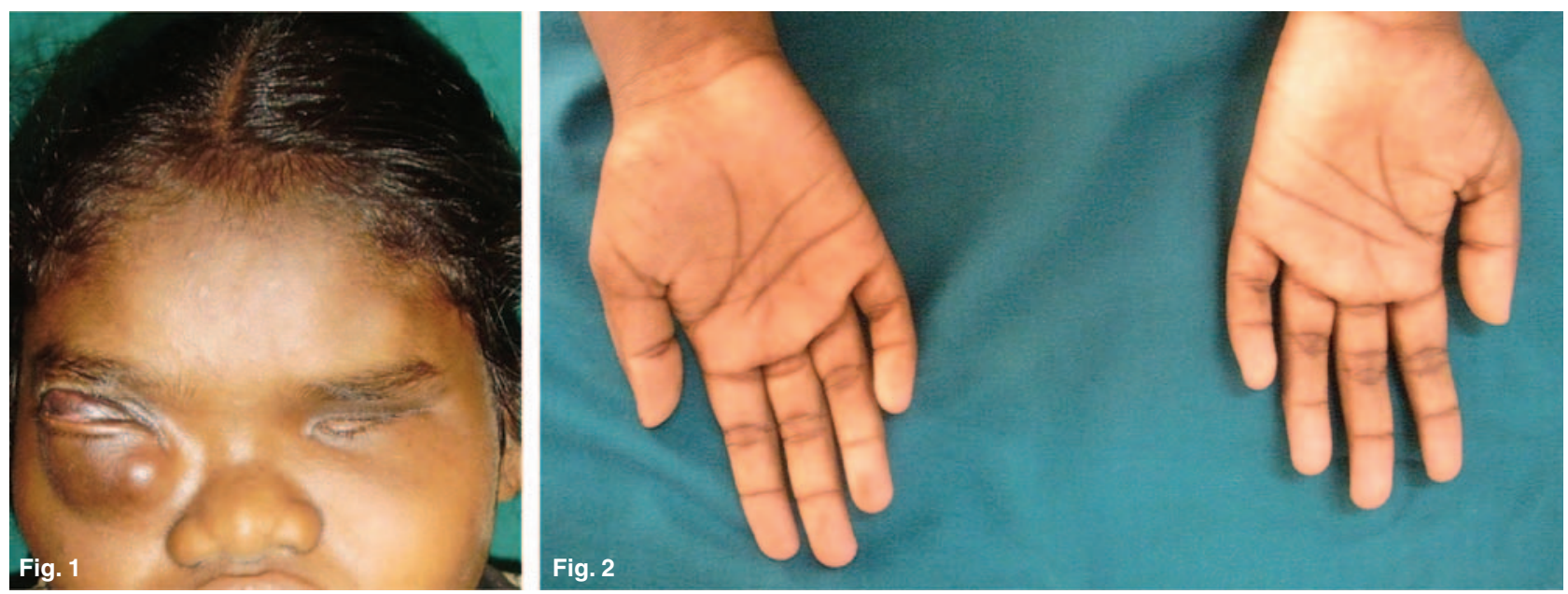

A 12 years old girl was referred for dental evaluation. Patient's parents reported swelling in the right eye for the past 6 months. On examination she had, microphthalmia (Fig. 1) along with orbital cyst with no pain or discharge. Other findings such as short stature, dry and rough skin, brachycephaly, depressed nasal bridge, and short philtrum. Clinodactaly of the fifth finger bilaterally (Fig. 2). Her IQ was below normal and she was uncooperative for examination and investigations. Her dental examination revealed crowding of teeth, anterior open bite and all the 3rd molar follicles were missing except right side mandible (Fig. 3).

The syndrome, described by Lenz et al.' in 1955, is a rare genetic disorder [1]. Cardinal features of the syndrome are unilateral or bilateral microphthalmia, ear deformities, microcephaly, dental, skeletal, urogenital abnormalities, and mental retardation [1-3].

There are no specific management strategies for this syndrome; it has to be managed in accordance with the congenital anomalies present in the individual patient by multiple specialties working in tandem. Orbital implants like that of polytetrafluoroethylene can be used [4].

\section{Ramachandran Sudarshan, Rajeshwari G. Annigeri}

Key words: Microphthalmia, clinodactyly, anterior open bite.

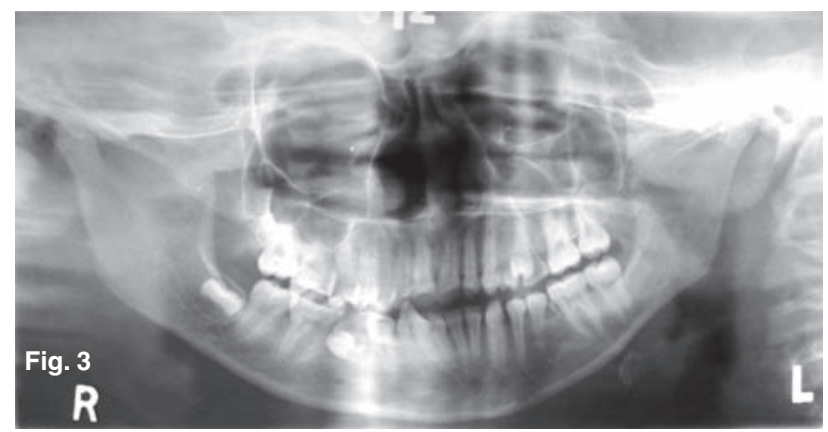

\section{Conflict of interest}

There is no conflict of interest.

\section{References}

1. Lenz W. Recessive, sex-limited microphthalmia with multiple abnormalities. Z Kinderheilkd 1955;77:384-90.

2. Traboulsi EI, Lenz W, Gonzales-Ramos M, Siegel J, Macrae WG, Maumenee IH. The lenz microphthalmia syndrome. Am J Ophthalmol 1988;105:40-5.

3. Glanz A, Forse A, Polomeno RC, Cole DE. Lenz microphthalmia: a malformation syndrome with variable expression of multiple congenital abnormalities. Can J Ophthalmol 1983;18:41-4.

4. Gupta A, Srinivasan R, Pandian DG, Babu KR. Lenz microphthalmic syndrome in an Indian patient. Indian J Ophthalmol 2007;55:462-3. 